Lösungen von übermangansaurem Kali, Borsäure und anderen desinfizierenden Substanzen, Tamponaden, Massagen haben wohl manchmal einen vorübergehenden Erfolg, vermögen aber in den meisten Fällen nicht einmal das für den Patienten und seine Umgebung lästigste Symptom dér Ozäna, den Fötor, zu beseitigen.

Die aus dem Institut für Krebsforschung von J. Tugendreich ${ }^{1}$ ) veröffentlichte Mitteilung über die Behandlung von Hautulzerationen bei Krebskranken mit Eucupin (Isoamylhydrocuprein) gab mir den Anlaß, einen Patienten, der wegen Leukämie dem Institut zur Röntgenbestrahlung überwiesen wurde und der seit mehreren Jahren an Ozäna litt, mit E u c u pi n $\mathrm{zu}$ behandeln.

Das Eucupin gehört zur Reihe der Chinaalkaloide, deren bakterizide und gleichzeitig anästhesierende Wirkung von Morgenroth und seinen Mitarbeitern $^{2}$ ) experimentell erforscht worden ist.

Erfolgreiche praktische Anwendung fand das Eucupin zuerst bei übelriechenden Hautulzerationen Krebskranker und mit ebenso gutem Erfolg bei Röntgenschädigungen der Haut (Tugendreich $\left.{ }^{3}\right)$ ). Bei diesen Affektionen wird das Eucupin in Form einer 2\%igen Salbe appliziert $\left.t^{4}\right)$. Vielfach wurden auch Suppositorien, die eine $2 \%$ ige Lösung des Eucupin basicum in Kakaobutter enthalten, bei verschiedenen Sshmerzzuständen im Rektum mit Erfolg angewandt. Ferner berichten Bra un ${ }^{5}$ ). So m mer ${ }^{6}$ ) und Pf eif er $^{7}$ ) über die günstige Wirkung des Eucupins bei lokaler Behandlung von Diphtheriebazillenträgern und Diphtheriekranken. Die experimentelle Giundlage ihrer Versuche bieten die Studien von Schaeffer ${ }^{8}$ ), durch welche die außeiordentlich starke Einwirkung des Eucupins auf Diphtheriebazillen in vitro nachgewiesen wurde. Angesichts der von Morgenroth und Tugendreich (l. c.) beschriebenen ausgeprägten bakteriziden Wirkung des Eucupins gegenüber den Streptokokken dürfte auch an eine Beeinflussung der so häufigen Streptokokken-Mischinfektion bei Diphtherie zu denken sein.

Bei dem bereits erwähnten Ozänakranken habe ich das

Aus dem Universitätsinstitut für Krebsforșchung der Kgl. Charité in Berlin.

(Leiter: Prof. Ferdinand Blumenthal.)

\section{Ueber die Behandlung der Ozäna mit Eucupin.} Von cand. med. R. Gassul.

Die Ozäna (Rhinitis chronica atrophica foetida) besteht bekanntlich in einer unaufhaltsam fortschreitenden Atrophie der Nasenschleimhaut mit ihren Gefäßen und Drüsen. Es bilden sich an der atrophierten Schleimhaut fest anhaftende, grünlich-gelbe Borken und Krusten, die durch faulige Zersetzung einen unerträglichen Geruch verbreiten.

Die Bakterienart, welche diese Schleimhauterkrankung oder die faulige Zersetzung verursacht, ist bis jetzt noch nicht mit Sicherheit festgestellt worden.

Von allen Mikroorganismen, die im Laufe der Zeit von verschiedenen Forschern aus der Nasenhöhle Ozänakranker gezüchtet worden sind, verdient der von F. Perez ${ }^{4}$ ) beschriebene Kokkobazillus den größten Anspruch, als mutmaßlicher Erreger der Ozäna angesehen zu werden.

Es gelang nämlich diesem Autor, mit dem von ihm entdeckten Virus ein der menschlichen Ozäna ähnliches Krankheitsbild bei Kaninchen experimentell zu erzeugen.

Die darauf basierende Behandlung der menschlichen Ozäna mit Kokkobazillenvakzine, wie sie von Hofer und Kofler ${ }^{5}$ ), $\operatorname{Mazza}^{6}$ ) und anderen beschrieben wurde, hat auch eine günstige Einwirkung auf den Krankheitsverlauf gezeitigt. Allerdings berichten die erwähnten Autoren über eine Anzahl von Fällen, die sich der Vakzination gegenüber refraktär verhalten haben. Bei diesen Fällen ließ sich weder der Fötor noch die Borkenbildung beeinflussen. Auch gab es Fälle, wo der Fötor nach der Behandlung an Intensität abnahm, die Borkenbildung aber noch fortdauerte.

Die übliche Therapie der Ozäna richtet sich aber vornehmlich auf eine Desinfektion der Nasenhöhle, sie ist in der Hauptsache eine lokale. Spülungen und Nasenduschen mit

1) Jahresbər. der Neuen Heilanstalt, Württemberg. med. Korr.BI $\left.{ }^{2}\right)$ M. m. W. 1914 Nr. 16 S. $857-859$. - B) D. m. W. 1913 Nr. 15.

4) Per ez, B. kl. W. 1913 Nr. 52. - 5) W. kl. W. 1916 Nr. 37. Hof er u. Kofler, Arch. f. Laryng. 1914 Bd. 29. - 6) W. kl. W. 1915 Nr. 18.
Eucupin bihydrochloricum in Form der 2\%, igen Salbe angewandt.

Es handelt sich um einen 48 Jahre alten Mann, der seit übe ${ }_{i}$ drei Jahren wegen Ozäna ohne jeglichen Erfolg behandelt wurde.

Die Untersuchung der Nasenhöhle vor der Behandlung ergab folgenden Befund: leichte Atrophie der rechten unteren Muschel mit Borkenbelag, grünlich-graue Krusten am Septum und an beiden mittleren Muscheln, blasse trockene Schleimhaut, starker Fötor.

Nach vorheriger Entfernung der lamellenartigen $K_{I} u$ ten mit der Kniepinzette führte ich in jede Nasenhöhle bis zur Pars olfactoria eineı Tampon (nach Gottstein) mit der dick aufgelegten Eucupinsalbe ein. Nach etwa 15-20 Minuten entfernte ich die Tamponade, die Salbe blieb an allen Flächen der Nasenschleimhaut haften. Diese Prozedur wurde täglich wiederholt. Nach der vierten Tamponade war laut Angabe des Patienten und auch objektiv eine Besserung insofern eingetreten, als der Fötor verschwunden war und auch die Borkenbildung nachgelassen hatte.

Nach 18 täglich wiederholten Eucupintamponaden und dreiwöchiger Pause ohne Behandlung war der Nasenbefund folgender: Nasenschleimhaut feucht, von normaler Farbe, keine Borken, absolut kein Fötor; Patient hat das vor der Behandlung bestandene trockene, brennende Gefühl in der Nase nicht mehr.

Nach drei Monaten ist kein Rezidiv aufgetreten. Das \&ubjektive und objektive Befinden des Patienten ist unverändert gut.

Mit ebenso gutem Erfolg habe ich noch weitere zehn Ozänapatienten, die uns Herr San.-Rat Dr. J. Hirsch zugewiesen hat, in derselben Weise mit Eucupinsalbe behandelt.

Ueber einige dieser Fälle, die als vorläufig geheilt angesehen werden können, möchte ich noch kurz berichten.

Frl. K., 27 Jahre alt, Anämie. Seit zehn Jahren lästige Borkenbildung mit penetrantem Geruch aus der Nase. Atrophie beider unteren Muscheln, namentlich der rechten; eine mit grünlichen Borken dicht belegte Szhleimhaut, die stellenweise blaß und atrophisch zum Vorschein kommt. Nach der Entfernung der Borken sieht man dellenförmige Ein-

1) B. kl. W. 1916 Nr. 10. - ${ }^{2}$ ) Morgen roth, B. kl. W. 1917 Nr. 3; M orgen roth und Gin s berg, B. kl. W. 1912 Nr. 46. 1913 Nr. 8; Morgenroth und Tugendreich, B. kl. W 1916 Nr 29; Bioch. Zschr. 79. 1917 H. 5 u. 6. ${ }^{3}$ ) l. c. u. Zschr. f Krebsforsch. 16 H. 1. 4) Rp. Eucupin bihydrochl. 2,0 Das Präparat Eucupin wird Solve in Aq. dest. $\quad 40,0$ von den Vereinigten ChininAdde Lanolin 40,0 $\begin{aligned} & \text { von den Vereinigten Chinin- } \\ & \text { fabriken Zimmer \& Co. in }\end{aligned}$ Vaselin aa ad 100,0 Frankfurt a. M. hergestellt.

- 5) Fortschr. d. Med. 1916/17 Nr. 7. - $\left.{ }^{6}\right)$ B. kl. W. 1916 Nr. 43. $\left.{ }^{7}\right)$ Fortschr. d. Med. 1916/17 Nr. 8. $-{ }^{8}$ ) B. kl. W. 1916 Nr. 38. 
drücke in der atrophischen Schleimhaut. Nach 20 Eucupintamponaden vollständiger Schwund der Borken und des Fötors.

Nasenbefund nach der Behandlung und 21/2 wöchiger Pause: keine Borken, feuchte Schleimhaut, kein Fötor. Die vor der Behandlung bestandenen Kopfschmerzen und Trockenheit in der Nase sind verschwunden.

Nach weiteren drei Monaten ohne Behandlung kein Rezidiv.

Herr R. P., 31 Jahre alt, Tbc. apicum, Anämie. Seit etwa vier Jahren widerlicher Ge uch aus der Nase mit Borkenbildung. Nasenbefund: atrophische, blasse Schleimhaut, trockene, fest anhaftende Krusten, starker Fötor.

Bereits nach neun Tamponaden hat die Krustenbildung völlig aufgehört und ist der Geruch gänzlich verschwunden. Nach weiteren sechs Tamponaden und einer Pause von $2 \frac{1}{2}$. Monaten $\mathbf{k}^{r}$ in Rezidiv.

Frl. A. R., 17 Jahre alt, Anämie. Seit 6-7 Jahren Beschwerden beim Atmen, Nase öfters verstopft, stark übelriechende Borken, die in langen Lamellen sich entfernen lassen. Nasenbefund: Atrophie der ganzen Schleimhaut beider Nasenhöhlen, fötide Krusten hauptsächlich an den unteren Muscheln. Geruchssinn abgeschwächt.

Nach 18 Tamponaden keine Borken, kein Fötor. Zwei Monate nach der Behandlung kein Rezidiv, die Schleimhaut ist feucht und von normaler Farbe.

Frl. M. W., 20 Jahre alt. Typischer Ozänabefund mit subjektiven Beschwerden. Nach 15 Eucupintamponaden Borkenschwund und völliges Sistieren des Fötors.

Zwei Monate nach der Behandlung ohne Rezidiv.

Es läßt sich freilich noch nicht sagen, ob es sich in allen diesen Fällen um eine definitive Heilung handelt. Immerhin sind die unmittelbaren Erfolge der Eucupinbehandlung so eklatant, daß es sehr wünschenswert wäre, wenn die Eucupinwirkung bei der Ozäna, namentlich in schwereren Fällen, nachgeprüft und die Anwendungstechnik weiter ausgebaut würde. 